\title{
Direct Anterior Screw Fixation in a Type II Odontoid Fracture with a Fused C2-C3: A Technical Report
}

\author{
Arvind Gopalrao Kulkarni, Tushar Satish Kunder \\ Mumbai Spine Scoliosis \& Disc Replacement Centre and Department of Orthopaedic Surgery, Bombay Hospital and Medical Research Centre, \\ Mumbai, India
}

Received: February 10, 2021

Revised: April 17, 2021

Accepted: May 16, 2021

Corresponding Author: Arvind Gopalrao Kulkarni, MS Mumbai Spine Scoliosis \& Disc Replacement Centre and Department of Orthopaedic Surgery, Bombay Hospital and Medical Research Centre, Room No. 206, 2nd Floor, New Wing, 12, Vitthaldas Thackersey Marg, Mumbai, Maharashtra 400020, India

Tel: +91-9892875490

Fax: +91-22-22080871

E-mail: HYPERLINK

"mailto:drarvindspines@gmail. com"drarvindspines@gmail.com
To describe an innovative technique of direct anterior screw fixation in type II odontoid fracture with a congenitally fused C2-C3 vertebrae. Direct anterior screw fixation for type II odontoid fractures restores $\mathrm{C} 1-\mathrm{C} 2$ rotatory movement and allows early rehabilitation. Conventionally this technique involves entry of the screw through the $\mathrm{C} 2-\mathrm{C} 3$ intervertebral space. The challenge in the described case was the absence of a working C2-C3 interspace. This is one of the first few reports of the use of the direct anterior screw approach in congenitally fused C2-C3 situation. An 18-year-old male suffered a post- traumatic Type II displaced odontoid fracture without any neurological deficits. This patient also had a congenitally fused C2-C3 vertebra. Direct anterior screw fixation was performed using the C3-C4 interspace with a $55 \times 3.5 \mathrm{~mm}$ partially-threaded-cannulated screw. The unusual long curvilinear trajectory owing to the fused C2-C3 vertebrae proved to be technically demanding. The patient tolerated the procedure well. Direct anterior screw fixation is a feasible option in type II odontoid fractures with congenitally fused C2$\mathrm{C} 3$ vertebrae. The subtle modifications required for this procedure are use of a longer screw and entry point at the $\mathrm{C} 3-\mathrm{C} 4$ interspace.

Key Words: Odontoid process, Fracture, Cervical spine, Spinal fracture, Trauma, Fracture fixation, Endoscopic surgery

\section{INTRODUCTION}

Direct anterior screw fixation described by Böhler and Nakanishi in 1982 has gained popularity as the treatment of choice for selected cases of type II odontoid fractures [1,2]. The advantage being restoration of the $\mathrm{C} 1-\mathrm{C} 2$ rotatory movement, this technique uses the C2-C3 interspace and the inferior aspect of $\mathrm{C} 2$ as the entry point for the odontoid screw [3]. Congenital fusion of $\mathrm{C} 2-\mathrm{C} 3$ in this setting poses a unique challenge in performing this procedure in view of a longer and curvaceous trajectory. The patient described in this case report successfully underwent an anterior screw fixation in type II odontoid frac- ture in the background of congenital C2-C3 fusion.

\section{CASE REPORT}

An 18-year-old male presented to the emergency department after a car accident with neck pain and difficulty in turning his neck. Clinical examination entailed no focal neurological deficits. CT scans revealed a Type II odontoid fracture with $6 \mathrm{~mm}$ posterior displacement and congenital fusion of the C2-C3 vertebral body (Figure 1). MRI revealed absence of cord injury (Figure 2). A plan for osteosynthesis with direct anterior screw fixation was made. 


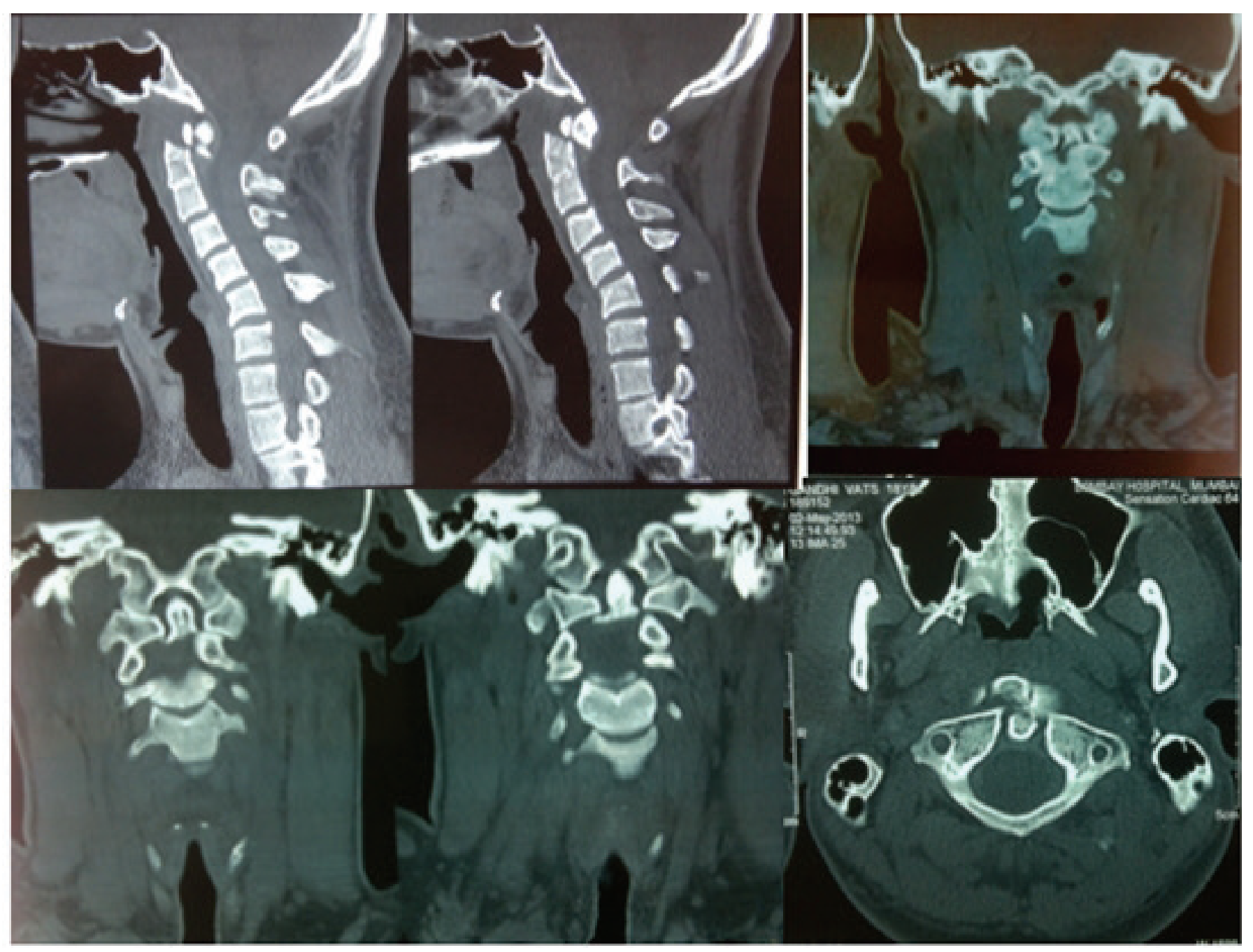

Figure 1. CT scans revealing Type II fracture of the odontoid with C2-C3 autofusion.

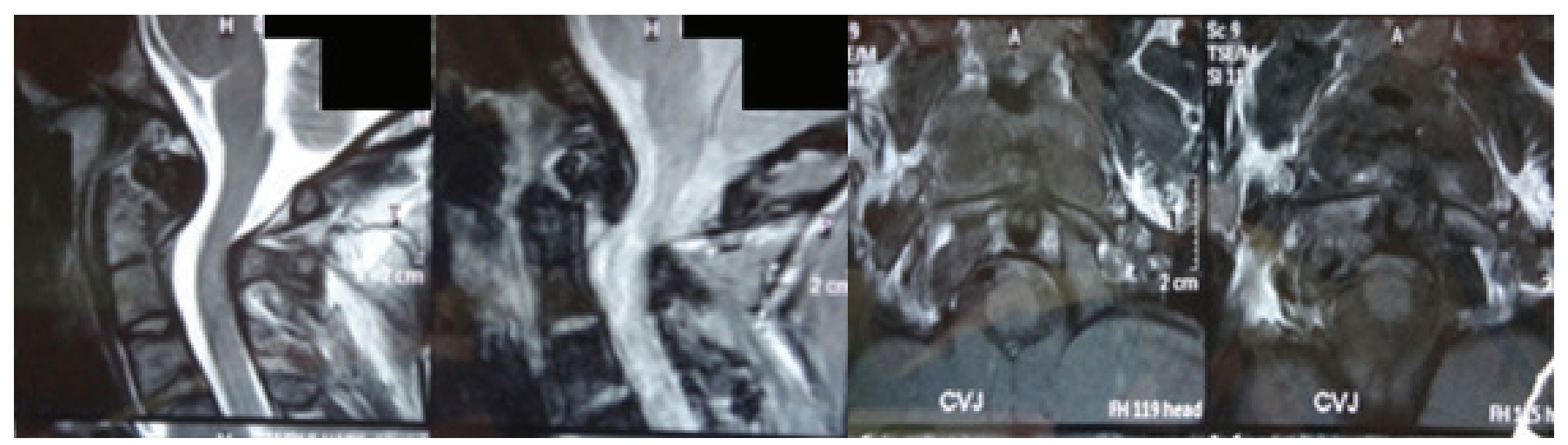

Figure 2. Pre-operative MRI scans of the patient.

\section{Operation}

A horizontal $2 \mathrm{~cm}$ incision over the skin crease was taken at the C5-C6 level. Anterior neck dissection was carried out between appropriate tissue planes. The C3-C4 interspace was localized using bi-planar fluoroscopy. A pilot hole was driven through the C3-C4 intervertebral space starting exactly in the midline at the inferior aspect of the $\mathrm{C} 3$ vertebral body. Re- 
duction manoeuvre was performed under anaesthesia with digital manipulation of the proximal fragment intra-orally under fluoroscopy guidance. The guide wire was driven using a power-drill through the proximal and distal fragments. The direction and the trajectory gets tricky in situations with C2-C3 fusion because the bony anatomy is rendered more curvaceous (Figure 3). A core drill was used followed by a tap to delineate the screw trajectory. A $55 \mathrm{~mm}$ length partially threaded $3.5 \mathrm{~mm}$ diameter cancellous screw was driven through the fracture, such that a strong purchase was achieved in the distal cortex to accomplish compression at the fracture site. Position of the screw was confirmed fluoroscopically. The wound was closed in layers following haemostasis and cosmetic sub-cuticular sutures were applied.

\section{Post-operative Course}

Patient was mobilized on the first post-operative day. Radiographs at 3 months post-surgery showed stable fracture union (Figure 4). CT imaging at 3 years post-surgery shows bony fusion at the fracture site (Figure 5, 6). Patient also retained full function at final follow up.

\section{DISCUSSION}

Direct anterior screw fixation in odontoid type-II fractures is an established treatment option [3]. This surgery not only provides excellent osteosynthesis and stability but also restores the rotatory movement at the $\mathrm{C} 1-\mathrm{C} 2$ joint in up to $83 \%$ of the patients, when compared to the other options of C1-C2 fusion
[4]. Other advantages include avoidance of the long posterior incision, immediate patient mobilization and short hospital stay

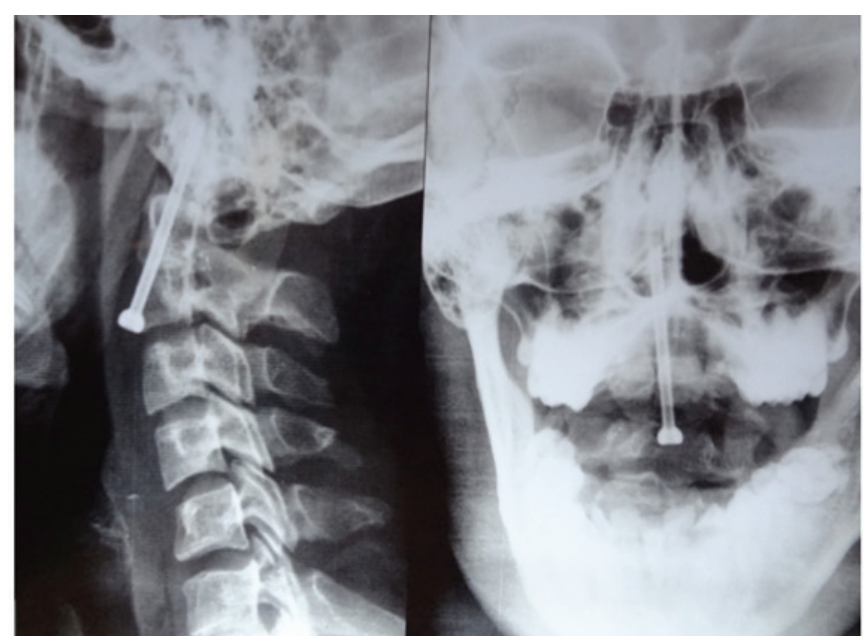

Figure 4. Radiograph at 3 months post-surgery-lateral and transoral AP views.

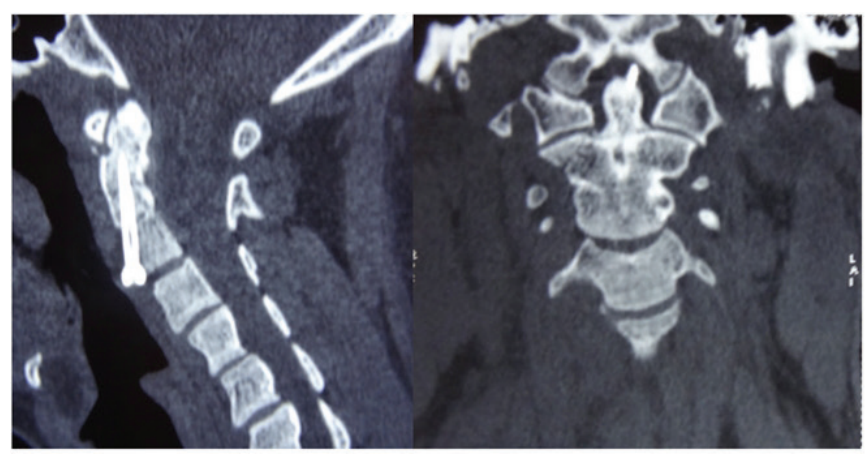

Figure 5. Coronal and sagittal CT scan at 3 years post-surgery.
Odontoid fracture fixation

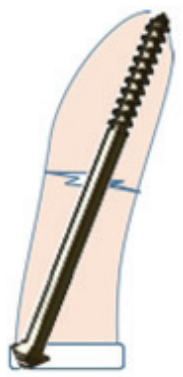

Odontoid fracture fixation in C2-C3 Vertebral body fusion

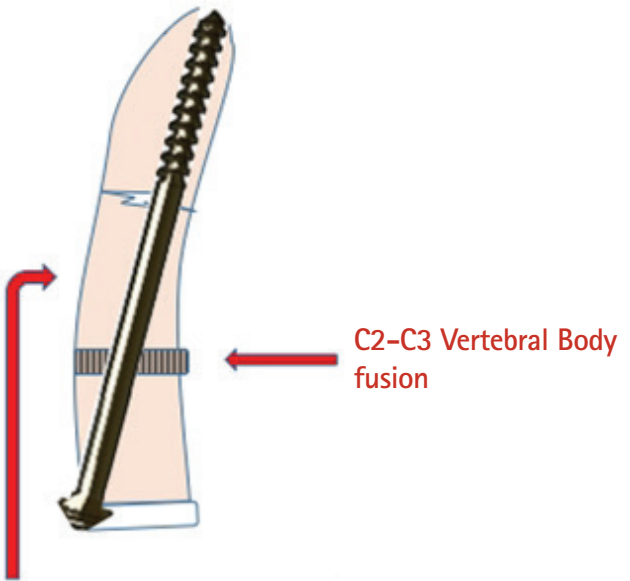

Longer screw trajectory in a curvaceous anatomy due to C2-C3 fusion

Figure 3. Illustration depicting the trajectory of the screw and the curvaceous anatomy of the vertebra in autofused C2-C3. 


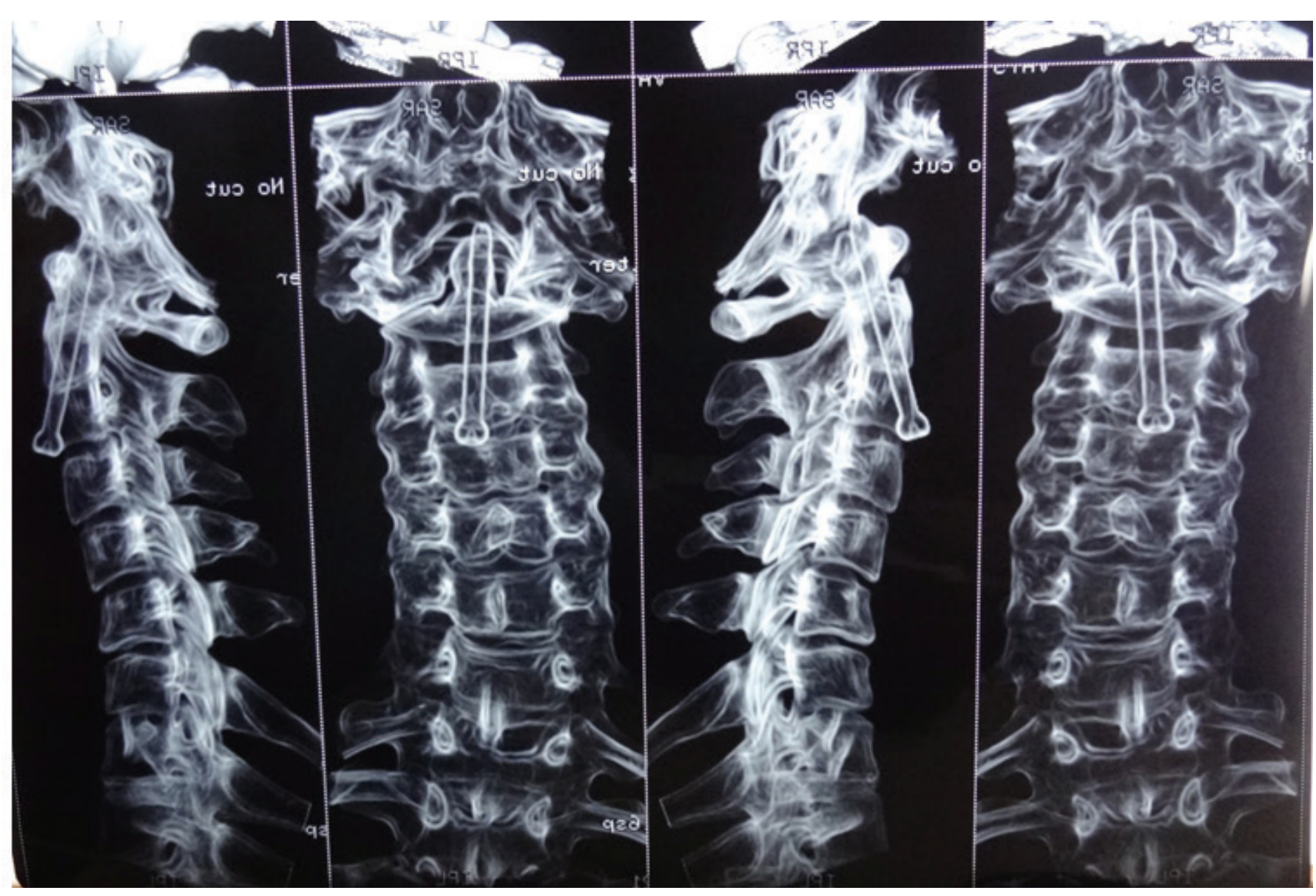

Figure 6. Digitally enhanced CT scan image showing the posteriorly fused C2-C3 vertebra with the screw in situ and the presence of first thoracic vertebra in view with the rib attachment.

[5-7]. The focal point of the technique is identifying the C2-C3 intervertebral space and using the inferior aspect of $\mathrm{C} 2$ vertebra for screw placement. This served as a stumbling block in the described patient who had a congenitally fused C2-C3. The prevalence of a fused C2-C3 is between $0.5 \%$ to $6.5 \%[8,9]$. The rarity of the condition is responsible for the limited literature on the same. This technique was historically contraindicated in patients with an inaccessible C2-C3 intervertebral space, necessitating a conservative approach or a posterior surgery [10]. This is only the second such case described in the literature [10]. Posterior surgery included either a trans-articular screw placement or a segmental lateral mass fixation and fusion [11]. The patient in this case report had a congenital C2-C3 fusion which meant absence of a normal motion segment at the C2C3 level. A fusion at C1-C2 as a treatment option, although not wide of the mark, would sacrifice vital movement of flexion and rotation at an additional adjacent level resulting in a stiff neck in a young individual. The motion preservation property of the direct anterior screw surgery prompted the authors to conceptualize the described technique in the patient. In this technique the C3-C4 intervertebral space was identified and the central and inferior aspect of the C3 vertebral body was used as the screw entry point. A longer than usual cannulated cancellous lag screw measuring $55 \mathrm{~mm}$ was used for the same in view of the longer trajectory. The authors emphasize the stocking of longer screws in the surgical armamentarium in such cases (generally, odontoid screws measure 35-45 mm in length) [12-14].

\section{CONCLUSION}

Direct anterior screw fixation is a feasible management option in patients with type II odontoid fractures in the background of a fused C2-C3. Use of a longer screw owing to the longer trajectory and the entry point at C3-C4 intervertebral space are the subtle modifications required to facilitate this procedure.

\section{CONFLICT OF INTEREST}

No potential conflict of interest relevant to this article. 


\section{REFERENCES}

1. Böhler J. Anterior stabilization for acute fractures and nonunions of the dens. J Bone Joint Surg Am 1982;64:18-27.

2. Nakanishi T. Internal fixation of the odontoid fracture. Cent Jpn J Orthop Trauma Surg 1980;23:399-406.

3. Apfelbaum RI, Lonser RR, Veres R, Casey A. Direct anterior screw fixation for recent and remote odontoid fractures. J Neurosurg 2000;93:S227-S236.

4. Montesano PX, Anderson PA, Schlehr F, Thalgott JS, Lowrey G. Odontoid fractures treated by anterior odontoid screw fixation. Spine (Phila Pa 1976) 1991;16:S33-S37.

5. Geisler FH, Cheng C, Poka A, Brumback RJ. Anterior screw fixation of posteriorly displaced type II odontoid fractures. Neurosurgery 1989 25:30-37. discussion 37

6. Montesano PX, Juach EC, Anderson PA, Benson DR, Hanson $\mathrm{PB}$. Biomechanics of cervical spine internal fixation. Spine (Phila Pa 1976) 1991;16:S10-S16.

7. Farrokhi MR, Rezaei H, Farrokhi F. Anterior screw fixation in type II odontoid fracture in an 18-month-old girl: a case report and review of the literature. Br J Neurosurg 2019;33:699702.
8. Shands AR Jr, Bundens WD. Congenital deformities of the spine; an analysis of the roentgenograms of 700 children. Bull Hosp Joint Dis 1956;17:110-133.

9. Soni P, Sharma V, Sengupta J. Cervical vertebrae anomalies-incidental findings on lateral cephalograms. Angle Orthod 2008;78:176-180.

10. Syed SH, Sindhu KK, Telfeian AE, Gokaslan ZL, Oyelese AA. Odontoid screw fixation of a type II odontoid fracture in a patient with autofused C2-C3 vertebral bodies. Interdiscip Neurosurg 2018;13:88-91.

11. Zhou F, Ni B, Li S, Yang J, Guo X, Zhu Z. C2 translaminar screw as the optimal choice for atlantoaxial dislocation with C2-C3 congenital fusion. Arch Orthop Trauma Surg 2010;130:15051509.

12. Heller JG, Alson MD, Schaffler MB, Garfin SR. Quantitative internal dens morphology. Spine (Phila Pa 1976) 1992;17:861866.

13. Doherty BJ, Heggeness MH. Quantitative anatomy of the second cervical vertebra. Spine (Phila Pa 1976) 1995;20:513-517.

14. Tun K, Kaptanoglu E, Cemil B, Yorubulut M, Karahan ST, Tekdemir I. Anatomical study of axis for odontoid screw thickness, length, and angle. Eur Spine J 2009;18:271-275. 